\title{
The relative influence of the different zones with fluid structure interaction on the dynamic behaviour of hydraulic machines
}

\author{
L'influence relative des différentes zones d'interaction fluide/structure \\ sur le comportement dynamique des machines hydrauliques
}

\author{
par A. Frei \\ Sulzer Pumps Winterthur
}

Dans les machines hydrauliques, le comportement interactif des joints annulaires et des roues à aubes joue un rôle important dans le comportement dynamique, qui s'ajoute à l'influence de l'arbre et des paliers. Par exemple, dans le cas d'une pompe haute vitesse qui alimente une chaudière à haute énergie, l'influence relative des différents joints annulaires et de l'interaction dans la roue à aubes est montrée et comparée à celle de la raideur de l'arbre et des paliers à coussinet-douille lubrifiés à l'huile. L'influence importante des éléments interagissant avec le fluide sur le comportement dynamique du rotor, la réponse déséquilibrée et la stabilité du rotor sont montrés. L'impact du frein de tourbillonnement à l'entrée du piston d'équilibrage sur la stabilité du rotor est également montré.

\section{INTRODUCTION}

1.1 Classification of fluid forces in a hydraulic turbo-
machine

When talking about fluid forces acting on the rotor of a hydraulic turbomachine, a classification of such forces needs to be done in order to clearly understand their influence on the dynamic behaviour of the rotor.

In fact, the lateral forces acting are of two kinds :

\subsubsection{Excitation forces}

These are forces which are always present when the rotor is turning, whether the shaft deflects or not. These forces are pure time functions. They can be broad band random forces due to turbulence, harmonic forces at rotational frequency due to mechanical or hydraulic unbalance, forces at higher harmonics of the rotational frequency, e.g. at vane passing frequencies, or subsynchronous periodic forces, e.g. from rotating stall at part load. These forces will impose vibrations on the rotor.

A typical fluid induced excitation force is hydraulic unbalance, which originates in unequal impeller blade loading due to tolerances in blade angle, blade pitch, and in impeller outlet width around the circumference. This force is mathematically expressed in an $x, y$ coordinate system orthogonal to the pump axis as

$$
\left\{\begin{array}{l}
F_{x} \\
F_{y}
\end{array}\right\}=U_{H} \omega^{2}\left\{\begin{array}{l}
\cos (\omega t) \\
\sin (\omega t)
\end{array}\right\}
$$

where the hydraulic unbalance is given by

$$
U_{H}=\frac{\rho \psi B_{2}^{*} D_{2}^{3} K_{H}}{8}
$$

For a precision cast impeller, $K_{H}$ is in the range of 0.01 to $0.02[1]$.

\subsubsection{Interaction forces}

These forces arise from dynamic rotor deflections, i.e. they arise as a response of the fluid to lateral rotor movements, and can formally be written

$$
\underline{F}=f(\underline{r}, \underline{r}, \underline{r})
$$


The above general nonlinear dependence is usually linearized about the static equilibrium position and the force is then proportional to rotor displacement (stiffness), vibration velocity (damping), or acceleration (mass). These forces contribute to the system behaviour (eigenvalues, mode shapes). They are expressed as follows :

$$
\left\{\begin{array}{l}
F_{x} \\
F_{y}
\end{array}\right\}=-\left[\begin{array}{ll}
k_{x x} & k_{x y} \\
k_{y x} & k_{y y}
\end{array}\right] \cdot\left\{\begin{array}{l}
x \\
y
\end{array}\right\}-\left[\begin{array}{ll}
c_{x x} & c_{x y} \\
c_{y x} & c_{y y}
\end{array}\right] \cdot\left\{\begin{array}{l}
\dot{x} \\
\dot{y}
\end{array}\right\}-\left[\begin{array}{ll}
m_{x x} & m_{x y} \\
m_{y x} & m_{y y}
\end{array}\right] \cdot\left\{\begin{array}{l}
\ddot{x} \\
\ddot{y}
\end{array}\right\}
$$

A schematic diagram of a multistage pump rotor indicating the major components generating lateral forces is presented in figure 1 .

This paper being dedicated to the interaction forces, in the following section these components will be discussed in brief.

\section{II - DISCUSSION OF INTERACTIVE FORCES}

\subsection{Journal bearings}

Forces in journal bearings can reasonably well be linearized for motions not exceeding about one third of the bearing clearance. Inertia forces are normally not significant, therefore the mass term in equation (4) is neglected. For a given bearing geometry and oil viscosity, stiffness and damping coefficients depend on rotor speed and static load, and are well known from experimental and theoretical work [2]. Computer codes to calculate the static as well as the dynamic behaviour are available.

\subsection{Thrust bearing}

Both tilting stiffness and damping are present at the thrust bearing. The coefficients depend on axial thrust. For proper modeling of the rotor, it is necessary to include these effects ; provided the residual thrust to be taken by the bearing is known. Little influence on rotordynamic behaviour has to be expected if the bearing is almost unloaded.

\subsection{Annular seals}

Dynamic coefficients of annular seals have to include the mass term, because flow conditions are typically turbulent. The dynamic coefficients do not depend very strongly on the static rotor position, as long as the static eccentricity does not exceed half of the clearance [3,4]. Under this condition the matrices 4) show an antimetric behaviour

\begin{tabular}{|c|c|c|}
\hline \multicolumn{3}{|c|}{ SYMBOLS } \\
\hline$B_{2}{ }^{*}$ & (m) & $\begin{array}{l}\text { Impeller width at outlet including } \\
\text { shrouds }\end{array}$ \\
\hline$c$ & (Ns/m) & Damping coefficient \\
\hline$D_{2}$ & (m) & Impeller diameter \\
\hline$e^{2}$ & (m) & Orbit radius \\
\hline$F$ & (N) & Force \\
\hline$g$ & $\left(\mathrm{~m} / \mathrm{s}^{2}\right)$ & Gravity constant \\
\hline $\mathrm{H}_{s}$ & (m) & Stage head \\
\hline$k^{s t}$ & $(\mathrm{~N} / \mathrm{m})$ & Stiffness coefficient \\
\hline$K_{H}$ & $(-)$ & Coefficient of hydraulic unbalance \\
\hline$m^{n}$ & (kg) & Mass coefficient \\
\hline$\underline{r}$ & (m) & $\begin{array}{l}\text { Lateral displacement vector : } \\
\underline{r}^{T}=\{x, y\}\end{array}$ \\
\hline$u_{2}$ & $(\mathrm{~m} / \mathrm{s})$ & Impeller peripheral speed \\
\hline$U_{H}^{2}$ & $(\mathrm{kgm})$ & Hydraulic unbalance \\
\hline$x^{H}$ & (m) & Lateral coordinate horizontal \\
\hline$y$ & (m) & Lateral coordinate vertical \\
\hline$\psi$ & $(-)$ & Head coefficient $=2 g H / u_{2}{ }^{2}$ \\
\hline$\rho$ & $\left(\mathrm{kg} / \mathrm{m}^{3}\right)$ & Fluid density \\
\hline$\omega$ & $(\mathrm{rad} / \mathrm{s})$ & Shaft angular speed \\
\hline$\Omega$ & $(\mathrm{rad} / \mathrm{s})$ & Orbit angular speed \\
\hline \multicolumn{3}{|c|}{ Indices : } \\
\hline$c$ & \\
\hline$r$ & \multirow{2}{*}{\multicolumn{2}{|c|}{ radial }} \\
\hline$t$ & \multirow{2}{*}{\multicolumn{2}{|c|}{$\begin{array}{l}\text { tangential } \\
\text { in } x \text {-direction }\end{array}$}} \\
\hline$x$ & & ction \\
\hline$y$ & \multicolumn{2}{|c|}{ in $y$-direction } \\
\hline
\end{tabular}

$\left\{\begin{array}{l}F_{x} \\ F_{y}\end{array}\right\}=-\left[\begin{array}{cc}k & k_{c} \\ -k_{c} & k\end{array}\right] \cdot\left\{\begin{array}{l}x \\ y\end{array}\right\}-\left[\begin{array}{cc}c & c_{c} \\ -c_{c} & c\end{array}\right] \cdot\left\{\begin{array}{l}\dot{x} \\ \dot{y}\end{array}\right\}-\left[\begin{array}{cc}m & 0 \\ 0 & m\end{array}\right] \cdot\left\{\begin{array}{l}\ddot{x} \\ \ddot{y}\end{array}\right\}$

The crosscoupled mass term is small and can normally be neglected.

Both experimental and theoretical work has been performed $[1,3,4,5]$ to identify the coefficients.

Computer codes are available to numerically calculate the coefficients. The code SEAL used to calculate the coefficients for the example shown in this paper is based on a thesis by S. Florjancic [6].

\subsection{Impellers}

Interactive forces in the space between eye- and pressure side annular seals are termed « impeller interaction" [7].

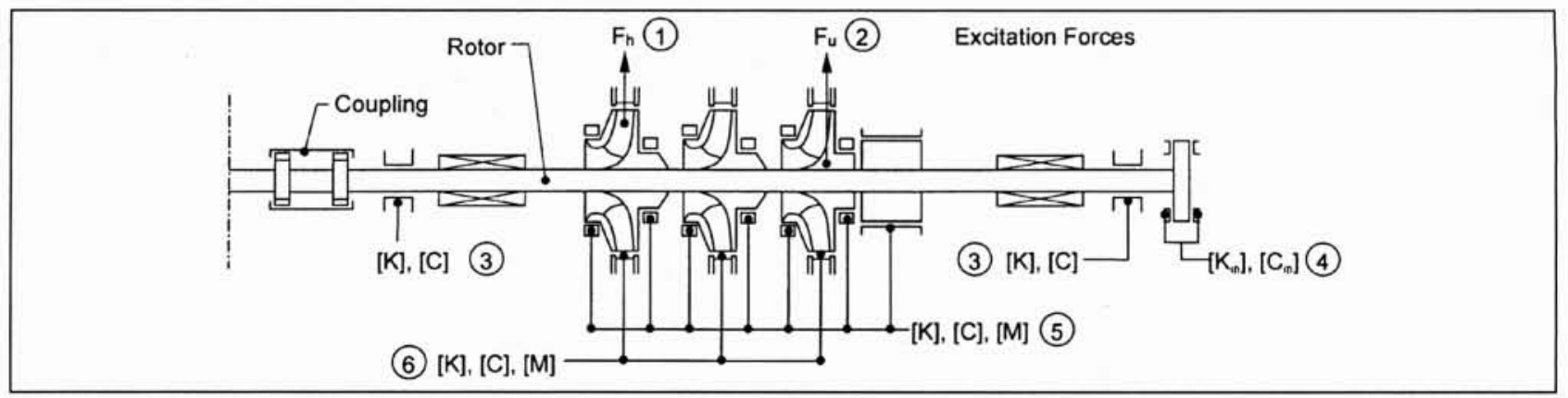

1. Schematic diagram and definition of dynamical forces acting on a Pump Rotor (Linearized Model). ; (1) Hydraulic excitation forces, (2) Unbalance excitation forces, (3) Coefficients for journal bearings, (4) Coefficients for thrust bearings, (5) Coefficients for annular seals, including balance piston, (6) Coefficients for impeller interaction. 
These forces show the same antimetric behaviour and are expressed in the same form 5) like annular seals; however, the crosscoupled mass term must not be neglected. Both experimental and theoretical work have been performed to identify the coefficients $[1,5,8]$. Navier-Stokes solvers are increasingly used to simulate the interactive behaviour [9]. The coefficients used in the example shown below are based on experimental work under an EPRI contract [1].

\subsection{Coupling}

The coupling has an effect on the system model. For short and fairly light flexible couplings, it is admissible to decouple the model of the pump rotor from the model of the drive. Usually one-half or one-third of the coupling spacer mass is added to the inboard shaft end, depending on the expected deflection pattern of the coupling. For long coupling spacers (e.g. with gas turbine as a driver) it may be necessary to include the entire shaft train in the model.

\section{INTERACTIVE BEHAVIOUR OF A HIGH SPEED MULTISTAGE PUMP ROTOR}

\subsection{Basic considerations}

The pump investigated is a high speed 6-stage boiler feed pump with barrel casing similar to the one shown on figure 2. Pump data is given in Table I. Rotordynamic coefficients have been assessed for journal bearings, impeller eye and pressure side seals, impellers, and balance piston. Rotor eigenmodes have been calculated using the Finite-Element based code MADYN [10].

To compare the interactive influence of the different pump components, it makes little sense to directly compare the individual coefficients, because it is the radial and tan-

Table 1. - Main data of pump.

\begin{tabular}{|l|c|}
\hline Impeller diameter $(\mathrm{m})$ & 0.28 \\
Number of stages & 6 \\
Quantity $\left(\mathrm{m}^{3} / \mathrm{s}\right)$ & 0.177 \\
Total head $(\mathrm{m})$ & 2700 \\
Speed $(\mathrm{rpm})$ & 6490 \\
Efficiency $(\%)$ & 84 \\
Water temperature (deg. C) & 180 \\
\hline
\end{tabular}

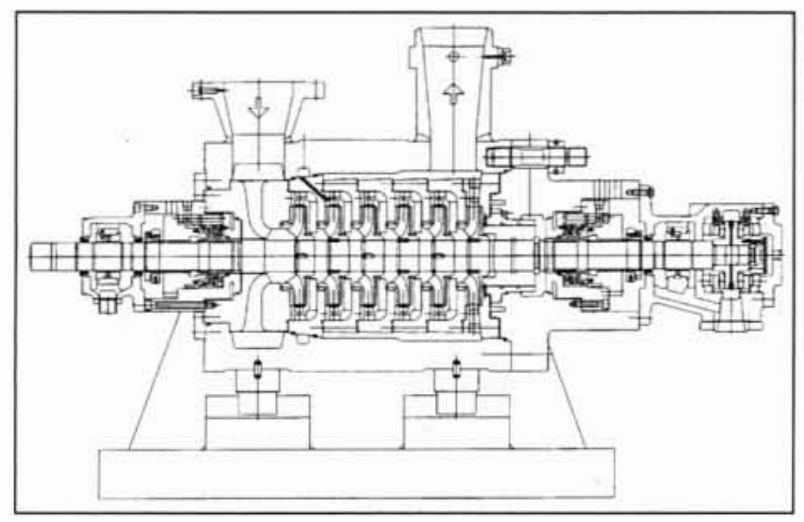

2. Longitudinal section of barrel casing pump. gential forces, i.e. the joint influence of all the coefficients, which determine the rotordynamic behaviour. To overcome this difficulty, we introduce the following quantities to compare the influence of the different components :

a) The radial and tangential forces for an assumed circular orbit with unit orbit radius and with a whirling angular frequency $\Omega$ equal to the angular shaft speed $\omega$, i.e. with a whirling motion as performed under the action of unbalance forces (synchronous orbit). The two forces show the centering/decentering as well as the damping/destabilizing capability of the different components under this synchronous orbital motion.

For annular seals and impellers, the radial and tangential forces per unit orbit radius derived from equation 5) write

$$
\begin{aligned}
& \frac{F_{r}}{e}=-k-c_{c} \Omega+m \Omega^{2} \\
& \frac{F_{t}}{e}=k_{c}-c \Omega
\end{aligned}
$$

with the sign convention that $\boldsymbol{F}_{\text {}}$ is positive when decentering, and $F_{t}$ is positive when driving (destabilizing). The forces $F r$ and $F t$ are constant in a coordinate system rotating with the orbital angular frequency $\Omega$, see figure 3 . Here in our case we set $\Omega=\omega$.

b) The « whirl frequency ratio " which is the ratio of orbital to running speed frequency below which the component becomes destabilizing, i.e. the net tangential force switches from damping (when the force vector is opposite to the vibration velocity vector) to destabilizing (when the force vector points in the same direction as the vibration velocity vector). At the whirl frequency ratio the net tangential force is zero.

For annular seals and impellers the condition $F_{t}=0$ according equation 7) leads to

$$
W F R=\left(\frac{\Omega}{\omega}\right)_{F_{t}=0}=\frac{k_{c}}{c \omega}
$$

The lower the whirl frequency ratio, the better. $W F R=0$ means that the component in question has inherent stabilizing characteristics. This is the case e.g. with tilting pad journal bearings.

\section{- 3.2 Comparison of the Interactive Behaviour of the Different Zones}

Interactive forces and whirl frequency ratios have been calculated for the following cases:

- Annular seals in «new » (design) condition, without swirl brakes.



3. Shaft orbit with radial and tangential forces. 
- Annular seals in « end of life " condition with $50 \%$ clearance enlargement :

a) without swirl brakes,

b) with swirl brake of the "shunt hole " type at the balance piston entrance,

c) in addition to b), with swirl brakes of the "radial slot » type at all suction side impeller siderooms.

Results are shown as bar charts, figures 4 and 5.

The following conclusions can be drawn :

\section{A) Radial and tangential forces for a synchronous orbit}

- For the assumed synchronous orbit, the journal bearings show centering as well as damping behaviour.

- All the annular seals are both centering and damping.

- The centering and damping capability of the balance piston is only slightly lower than that of one bearing.

- The centering capability of the total of all impeller eyeand pressure side seals is equal to the one of the balance piston; the damping capability is lower.

- Centering and damping forces of the annular seals reduce with increased clearance at « end-of-life » condition.

- The damping force of impeller eye seals and balance piston can be strongly increased by means of a swirl brake.

- Impeller interaction is both decentering and driving (destabilizing), the absolute magnitude is about one order of magnitude lower than for one bearing.

- Shaft stiffness is about one order of magnitude lower than radial bearing stiffness.

\section{B) Whirl frequency ratio}

- The journal bearing selected (fixed four-lobe type) has a whirl frequency ratio of 0.44 , which is within the expected range for such bearings ( 0.4 to 0.5 ).

- The impeller eye seals have a relatively high whirl frequency ratio of 0.8 to 0.9 , and thus have bad stabilizing pro-
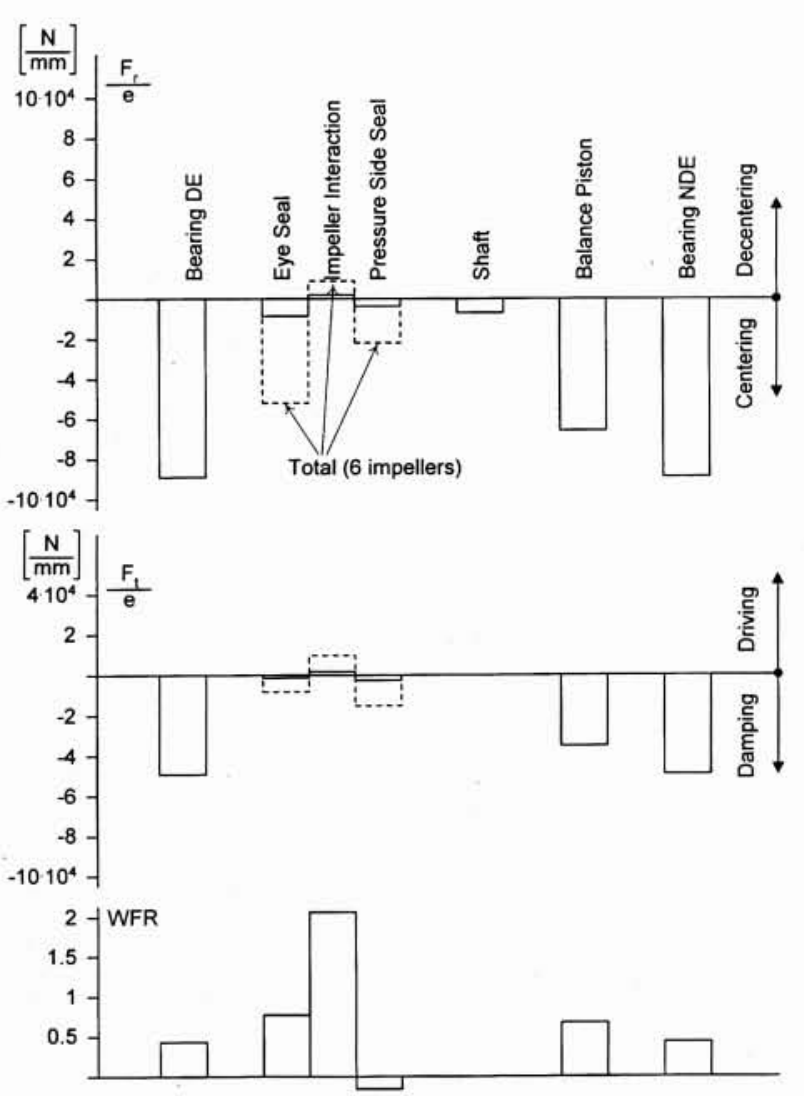

4. Radial and tangential forces for a synchronous orbit and whirl frequency ratio for « NEW » condition. perties. This is due to the high water prerotation at the entrance. By means of a swirl brake (radial slots), the whirl frequency ratio can be reduced to about 0.5 .

- The pressure side seals show a slightly negative whirl frequency ratio, and hence have inherent stabilizing properties. This is due to nil prerotation at the entrance because of the return channel vanes guiding the flow in purely radial direction.

- The balance piston has a whirl frequency ratio of some 0.75 without swirl brake, and of 0.25 with swirl brake. Hence the damping capability of the balance piston can be strongly increased by means of the swirl brake (« shunt hole » type).

- Without swirl brakes, the whirl frequency ratio of both the impeller eye seals as well as the balance piston raises with increasing clearance, i.e. these seals become more destabilizing at end of life condition.

- The destabilizing effect of the impeller interaction manifests in a high whirl frequency ratio of over two.

Table 2 shows the first critical speed in air as well as the least damped modes for the four cases investigated.

The first critical speed in air is much lower than the running speed; we have

$$
\frac{1 \text { st } \text { critical in air }}{\text { running speed }}=0.38
$$

Hence we are talking of a very flexible rotor: the influence of the shaft stiffness on rotordynamic behaviour in water is small [11].

The modes in water are supersynchronous (running speed frequency is $6490 / 60=108 \mathrm{~Hz}$ ). Note that both frequency and damping drop with increasing clearance. With swirl brakes at the impeller eye seals and the balance piston, damping at " end of life " condition can be lifted beyond the value for «new " condition without such swirl brakes. Note that a swirl brake at the balance piston alone does not have a
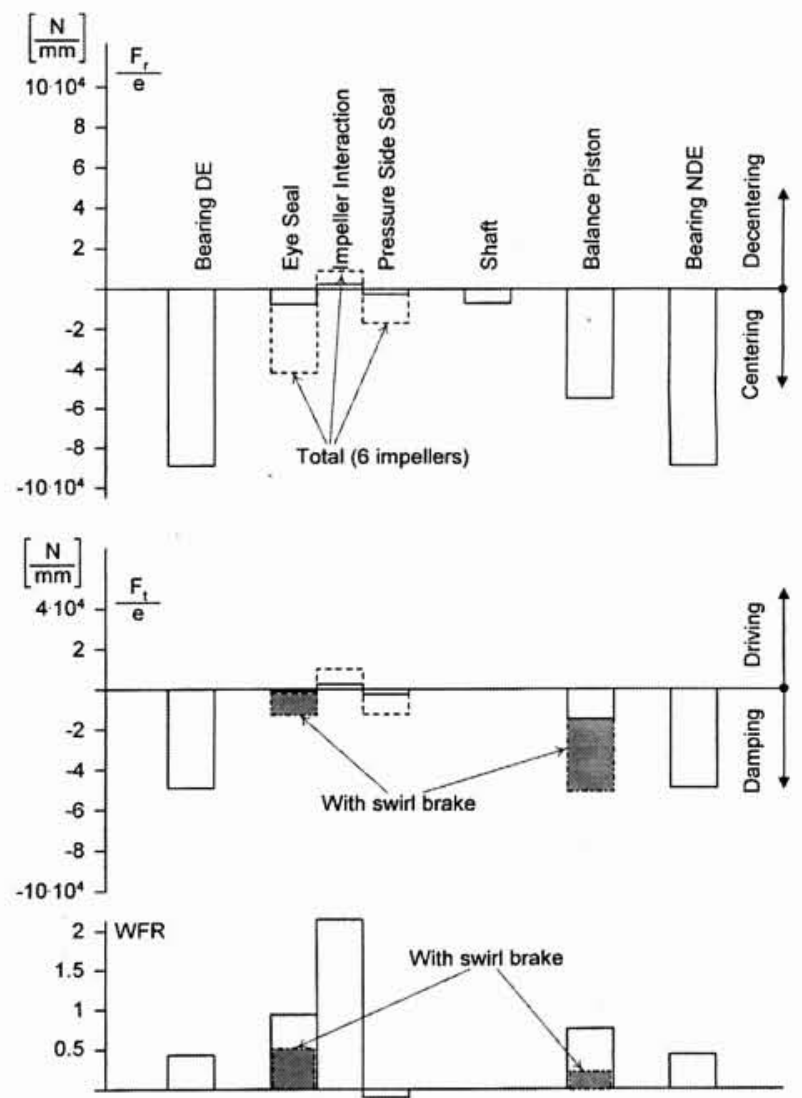

5. Radial and tangential forces for a synchronous orbit and whirl frequency ratio for « END OF LIFE » condition. 
Table 2. - Results of rotordynamic investigation.

\begin{tabular}{|l|l|l|}
\hline $\begin{array}{l}\text { 1st critical in air } \\
\text { Least damped modes : }\end{array}$ & $2440 \mathrm{rpm}$ & \\
$\begin{array}{l}\text { without swirl brakes } \\
\text { wew nouncy }\end{array}$ & $132 \mathrm{~Hz}$ & $12.1 \%$ \\
$\begin{array}{l}\text { a) Without swirl brakes } \\
\text { b) With swirl brake at }\end{array}$ & $122 \mathrm{~Hz}$ & $6.9 \%$ \\
$\begin{array}{l}\text { balance piston entrance } \\
\text { c) With swirl brakes at } \\
\text { balancepiston \& all impeller } \\
\text { siderooms }\end{array}$ & $125 \mathrm{~Hz}$ & $8.5 \%$ \\
\hline
\end{tabular}

a) Critical damping ratio.

big influence on modal damping, in spite of the significant reduction of the whirl frequency ratio. This becomes evident when looking at the mode shape for the case « end of life case b) ", figure 6. There is only a small vibration amplitude at the balance piston, because of the strong centering action. The two journal bearings force this mode to develop vibration nodes in the vicinity of the bearing locations.

As a conclusion it can be stated that for multistage pumps there are the annular seals which dominate the rotordynamic behaviour.

\section{DCOMPARISON WITH A FRANCIS TURBINE}

The results for the high speed multistage pump described above shall be compared with those for a Francis turbine described in [12]. A longitudinal section of this turbine is shown on figure 7. What is striking is the thick, stiff shaft. In fact, according to [12] the first critical speed in air of this turbine/generator rotor is twice as high as the running speed:

$$
\frac{1 \text { st } \text { critical in air }}{\text { running speed }}=2
$$

Hence, in contrary to the multistage pump, it is the shaft stiffness, in conjunction with the journal bearing behaviour, which determines the rotordynamic comportment. Consequently, annular seals and impeller interaction are of less importance for this turbine. Rotordynamic behaviour is typi-

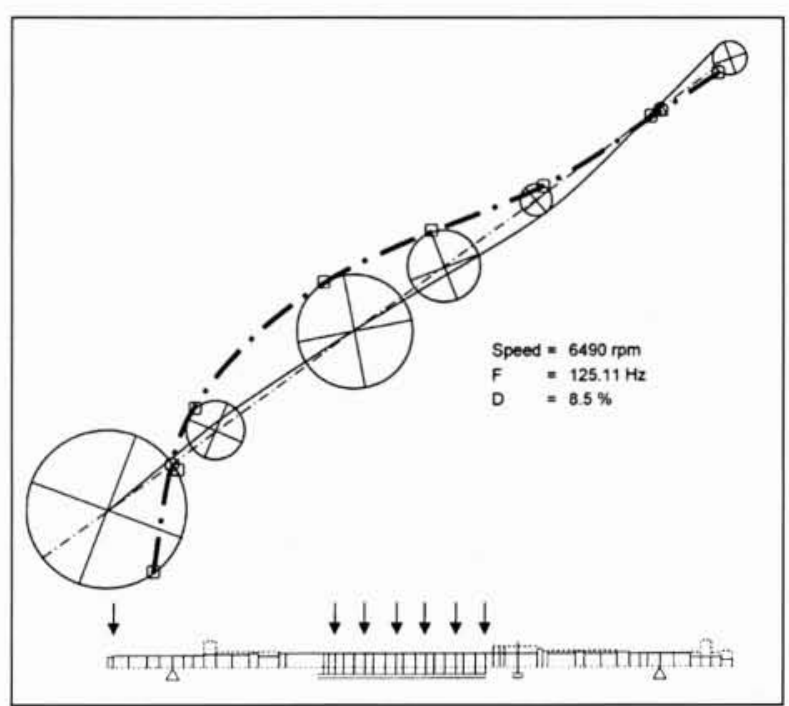

6. Least damped bending mode for « END OF LIFE " condition. cally of relatively little concern. This does not mean that the dynamic shaft behaviour shall not be carefully monitored during operation e.g. by means of proximity probes, because of the high cost and the time involved in case of a damage.

\section{REFERENCES}

[1] Bolleter U, et al. - Rotordynamic Modeling and Testing of Boiler Feed Pumps EPRI Report TR-100980, September 1992 ; Electric Power Research Institute, Palo Alto, California 94304.

[2] FRENE J. et al. - Lubrification Hydrodynamique. Edition Eyrolles, Paris 1990.

[3] Simon F., Frene J.. - Analysis of Incompressible Flow in Annular Pressure Seals. Journal of Tribology, July 1992, pp. $431 \mathrm{ff}$.

[4] Nordmann R., Dietzen F.J.. - Finite Difference Analysis of Rotordynamic Seal Coefficients for an Eccentric Shaft Position. Proceedings IMechE 1988 No. C317/88.

[5] CHILDS D.. - Turbomachinery Rotordynamics. John Wiley \& Sons, NY 1993.

[6] Florjancic S. - Annular Seals of High Energy Centrifugal Pumps: A New Theory and Full Scale Measurement of Rotordynamic Coefficients and Hydraulic Friction Factors. Doctoral thesis ETH Zurich No. 9087.

[7] Bolleter U. et al. - Hydraulic Interaction and Excitation Forces of High Head Pump Impellers. EPRI Publication 1989 ; Electric Power Research Institute ; Palo Alto, California 94304.

[8] Fongang R. et al. - Investigation of Hydrodynamic Forces on Rotating and Whirling Centrifugal Pump Impellers. ASME Paper 96-GT-18.

[9] BASHKharone E. - Rotordynamic Characteristics of Shrouded Pump Impellers. Texas A\&M Report TRCRD-1-92.

[10] MADYN Rotordynamic Computer Code, Ing. büro Klement, Alkmaarstr. 37, D-6100 Darmstadt 13.

[11] Frei A., Bolleter U. - The Influence of Shaft Stiffness on Balance Quality and Operating Reliability of Pumps. Proceedings Pumpentagung Karlsruhe 1992, Paper No. A 4-04.

[12] Bolleter U. et al. - On the Rotordynamics of Compressors, Pumps and Hydraulic Turbines. Proc. 3rd IFToMM Conference, October 12-14, 1989, Karlovac Yugoslavia.

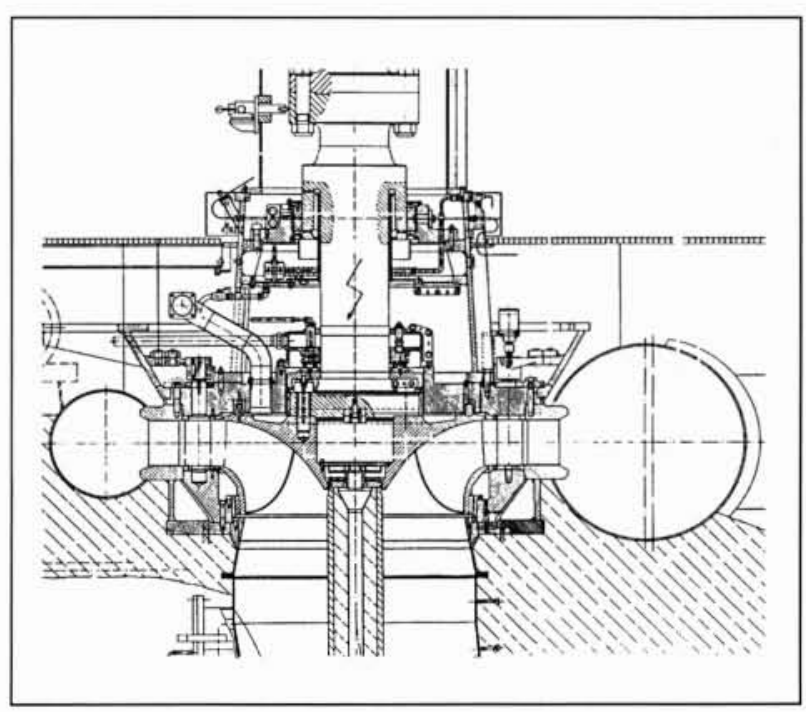

7. Cross section of a turbine [12]. 